\title{
Mediastinal Pancreatic Pseudocyst Caused by Obstruction of the Pancreatic Duct Was Eliminated by Bromhexine Hydrochloride
}

\author{
Tatsuhiro Tsujimoto, Masato TAKano, Takuya Tsuruzono, Kazushige Hoppo, \\ Yoshinobu MATSUMURA, Jyunichi YAMAO*, Shigeki KURIYAMA** and Hiroshi FUKUI*
}

\begin{abstract}
A 49-year-old man, who had a 30-year history of drinking the equivalent of $80 \mathrm{~g}$ of ethanol per day, underwent a detailed medical examination for cough and dyspnea. Chest-abdominal computed tomography and endoscopic retrograde pancreatography led to the diagnosis of a mediastinal pancreatic pseudocyst resulting from obstruction of the pancreatic duct by a protein plug. The pseudocyst rapidly improved with conservative treatment with camostat mesilate, $\mathrm{H}_{2}$-receptor antagonist and digestive enzymes. Although the patient abstained from alcohol for approximately 6 months, he resumed drinking, leading to recurrent attacks of pancreatitis. Bromhexine hydrochloride was then administered for 6 months, with the expectation that it would have a mucolytic effect on the pancreatic juice, resulting in improvement in the clinical symptoms, pancreatic enzymes and pancreatic exocrine function, as well as elimination of the protein plug. Bromhexine hydrochloride may be a new therapy for pathological states, such as alcoholic chronic pancreatitis, in which there is increased viscosity of the pancreatic juice because of elevated protein concentration, leading to protein plug formation and temporary blockage of the pancreatic duct.

(Internal Medicine 43: 1034-1038, 2004)
\end{abstract}

Key words: alcohol, bromhexine hydrochloride, chronic pancreatitis, mediastinal pancreatic pseudocyst, protein plug

\section{Introduction}

In alcoholic chronic pancreatitis there is an increased concentration of protein in the pancreatic juice as a result of the long-term alcohol intake, and this is considered to increase the viscosity of the pancreatic juice, leading to the formation of a protein plug that blocks the pancreatic duct and causes recurrent attacks of pancreatitis. Bromhexine hydrochloride is a bronchial mucolytic that also has an affinity for acinar cells, causing these cells to secrete low-viscosity pancreatic juice. We report a case of alcoholic chronic pancreatitis in which a mediastinal pancreatic pseudocyst was the result of obstruction of the pancreatic duct. After 5 months of treatment with bromhexine hydrochloride, the plug was eliminated.

\section{Case Report}

A 49-year-old man with a 30-year history of drinking the equivalent of $80 \mathrm{~g}$ of ethanol per day attended his local clinic with a cough that had started in late May 2000. His symptoms had not improved after treatment for the common cold, and when he also developed dyspnea and chest pain he presented to hospital in June. Chest radiography revealed extensive pleural effusion, and the patient was admitted for further investigation. On admission, hematology studies indicated a marked inflammatory reaction: white blood cell count $16,240 / \mu$ l with $78 \%$ neutrophils, erythrocyte sedimentation rate $77 \mathrm{~mm} / \mathrm{h}$ and C-reactive protein concentration 26.6 $\mathrm{mg} / \mathrm{dl}$. Pancreatic enzymes were elevated: serum amylase $1,648 \mathrm{IU} / l$, lipase $600 \mathrm{IU} / l$, trypsin $820 \mathrm{ng} / \mathrm{ml}$ and elastase 1 $1,300 \mathrm{ng} / \mathrm{dl}$. Urinary amylase was also elevated at 10,132 IU/ $l$. The pleural effusion appeared bloody and was positive for the rivalta reaction. Pancreatic enzyme levels in the pleural

\footnotetext{
From Department of Gastroenterology, Ishinkai Yao General Hospital, Yao, *Third Department of Internal Medicine, Nara Medical University, Kashihara and **Third Department of Internal Medicine, Kagawa University School of Medicine, Kagawa

Received for publication January 20, 2004; Accepted for publication July 6, 2004

Reprint requests should be addressed to Dr. Tatsuhiro Tsujimoto, Department of Gastroenterology, Ishinkai Yao General Hospital, 1-41 Numa, Yao, Osaka 581-0036
} 

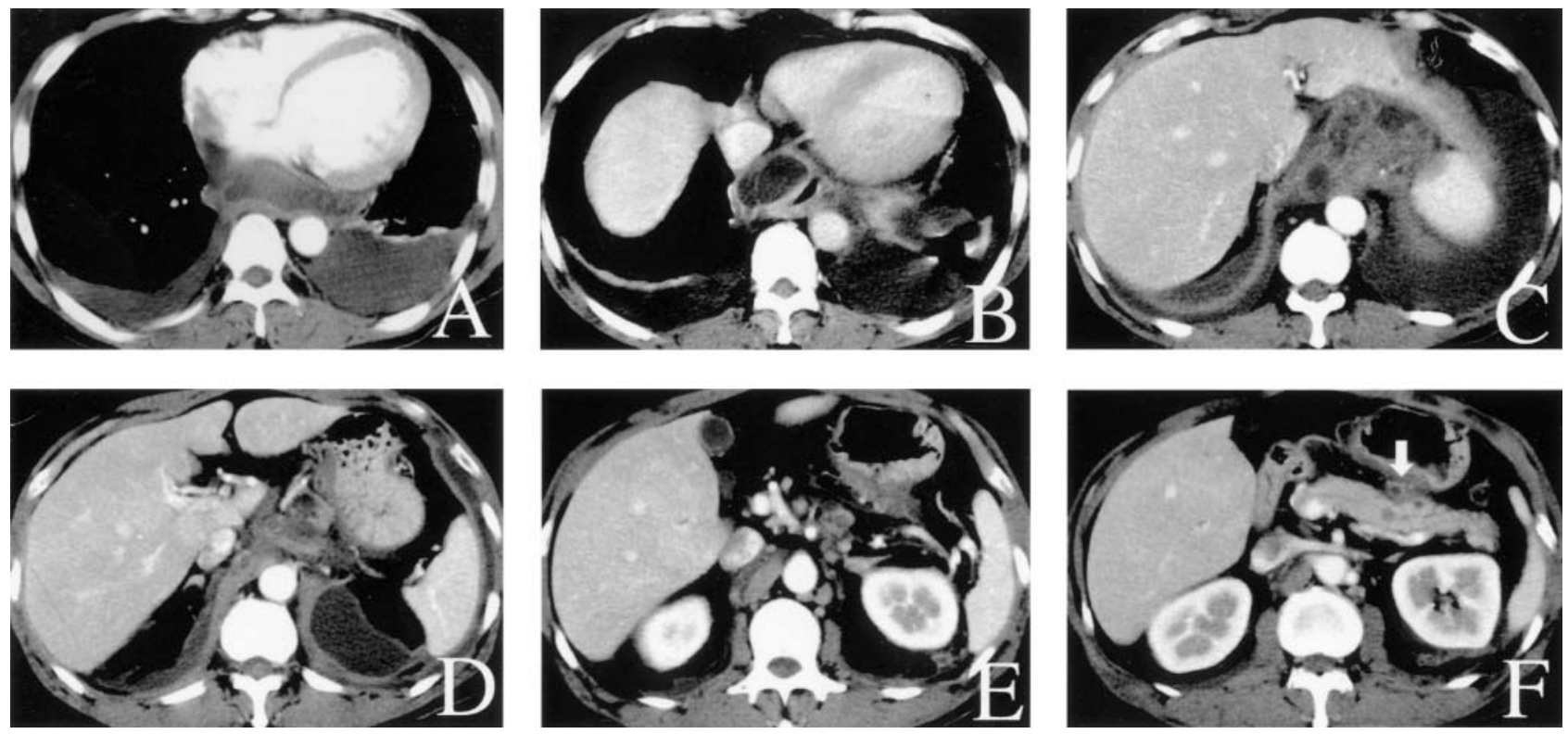

Figure 1. Chest-abdominal computed tomography on admission. (A) Bilateral pleural effusion is present, predominantly on the left side. (B) Continuous with the pleural effusion, there is a cystic lesion with a septum located in the mid-mediastinum on the right side of the esophagus, (C) with cloudy, cystic fatty tissue underneath. (D) More cystic lesions with septa can be seen in the left and right posterior peritoneal cavity. (E) From the periphery to the upper end of the gland the cystic fatty tissue appears cloudy. (F) The pancreatic duct in the body is dilated, and there is a lesion suggesting an internal fistula (arrow) on the ventral side.

effusion were elevated: amylase 19,780 IU/l, lipase 1,170 $\mathrm{IU} / l$, trypsin $1,220 \mathrm{ng} / \mathrm{ml}$ and elastase 1 1,400 IU/l. Ultrasonography revealed a cystic lesion with a septum, $5.7 \times 2.8$ $\mathrm{cm}$ in size, located in the left posterior peritoneal cavity and another lesion, $4.7 \times 2.3 \mathrm{~cm}$ with solid and cystic segments, located on the right side immediately below the esophagogastric mucosal junction.

Chest abdominal enhanced computed tomography (CT) showed bilateral pleural effusions, more pronounced on the left side. In the mid-mediastinum, to the right of the esophagus, there was another cystic lesion with a septum, which appeared to be continuous with the pleural effusion and associated with the cloudy, cystic fatty tissue beneath it. Other cystic lesions, each with a septum, were located in the left and right posterior peritoneal cavity. The pancreatic duct in the body of the gland was dilated, and there was a lesion suggestive of an internal fistula on the ventral side. From its periphery to the upper part, the cystic fatty tissue appeared cloudy (Fig. 1). Because the patient's general condition was good, the initial treatment regimen comprised antibiotics, a proteolytic enzyme inhibitor and an $\mathrm{H}_{2}$-receptor antagonist. By the 21st day of admission, the bilateral posterior mediastinal and peritoneal cysts and the pleural effusion had almost disappeared. As the results of various investigations had also improved, endoscopic retrograde pancreatography (ERP) was performed on the 22nd day of admission. The main pancreatic duct in the body was dilated, and there was a small transparent object within its lumen, suggestive of a protein plug. The lumen of the duct from the site of dilation toward the tail appeared irregular (Fig. 2A, B). Plain CT scanning performed immediately after ERP revealed accumulation of contrast material within the duct, and a transparent object within the dilated pancreatic duct at the same site as seen at ERP (Fig. 2C, D). These findings suggested acute aggravation of chronic pancreatitis: that is, the protein plug had lead to an anterior rupture of the pancreatic duct, and through this internal fistula the pancreatic juice had leaked into the abdominal cavity, forming cysts in the posterior peritoneal cavity. The pancreatic juice had also entered the mediastinum and thoracic cavity through an esophageal hiatus, again forming cysts. After discharge from hospital, the patient continued to abstain from alcohol while taking camostat mesilate $(600 \mathrm{mg} /$ day $)$, an $\mathrm{H}_{2}$-receptor antagonist, and digestive enzymes. He remained in good general health, but resumed drinking in November 2000 and suffered another attack of acute pancreatitis in December. ERP at the time revealed a dilated main pancreatic duct in the body and a transparent object, suggestive of a protein plug, in the lumen. Abdominal plain CT performed immediately after ERP showed accumulation of contrast material and a transparent object in the lumen of the duct at the site seen on the ERP image. The patient continued to drink, even after this episode, suffering from persistent epigastric and back pain. After obtaining informed consent from the patient, who was unable to abstain from drinking, we added bromhexine hydrochloride $(12 \mathrm{mg} / \mathrm{day})$ to his existing treatment regimen 

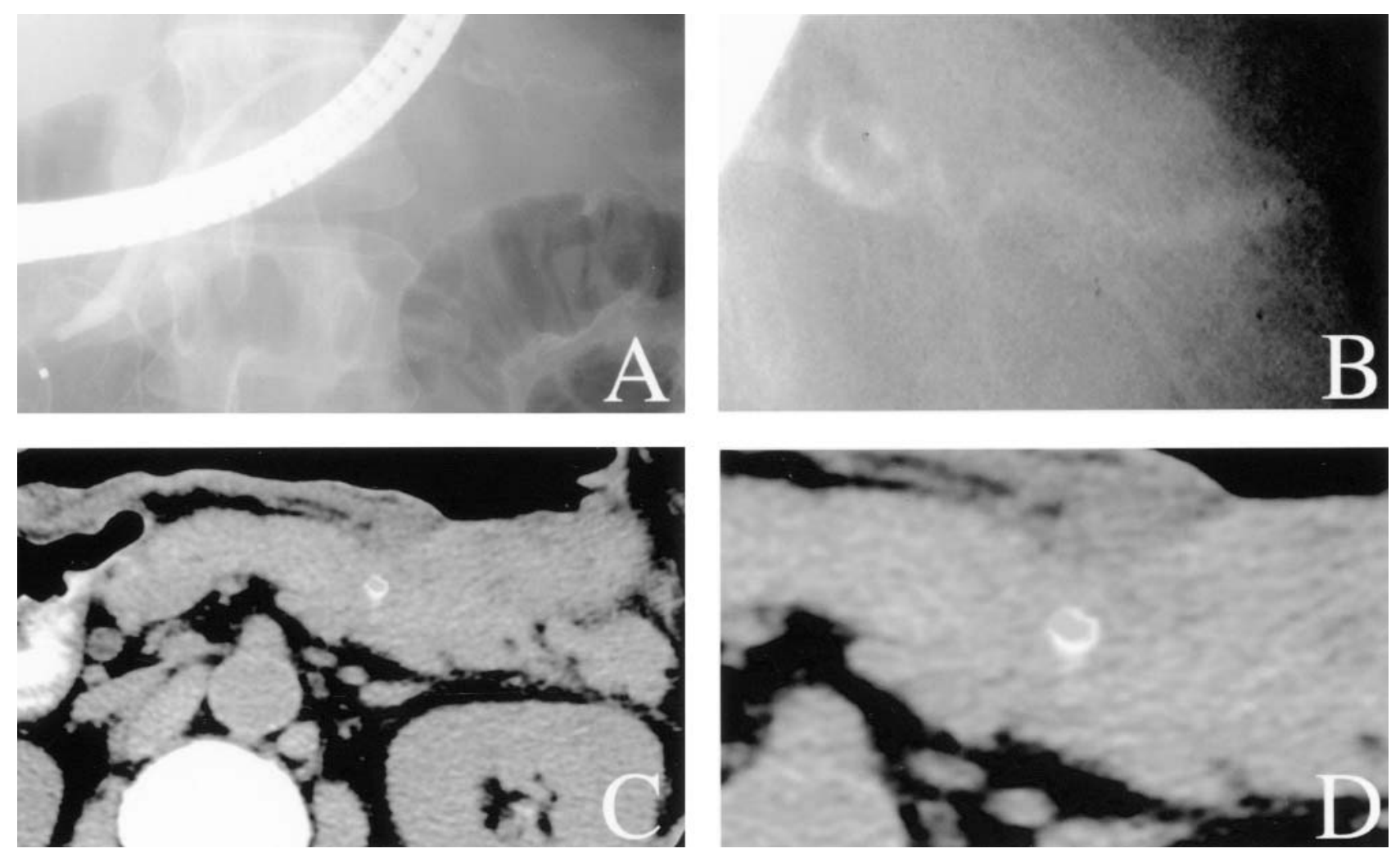

Figure 2. Endoscopic retrograde pancreatography (ERP) image and abdominal plain computed tomography (CT) taken immediately after ERP. (A, B) ERP: the main pancreatic duct in the body is dilated, and there is a small transparent object, suggesting a plug, inside the lumen. The main pancreatic duct lumen from the dilation toward the tail appears irregular. $(\mathrm{C}$, D) Abdominal plain CT taken immediately after ERP: there is an accumulation of contrast material within the duct with the transparent object visible at the site where the pancreatic duct was observed to be dilated on the ERP image.

for 5 months, in expectation of its mucolytic effect on the pancreatic juice. His clinical symptoms (epigastric and back pain) improved and so did the concentrations of pancreatic enzymes: serum amylase fell from 428 to $261 \mathrm{IU} / l$, lipase from 107 to $67 \mathrm{IU} / l$, trypsin from 670 to $107 \mathrm{ng} / \mathrm{ml}$, elastase 1 from 440 to $230 \mathrm{ng} / \mathrm{dl}$, and urinary amylase from 1,980 to $640 \mathrm{IU} / \mathrm{l}$. Fecal chymotrypsin also improved from 16.3 to 21.6 units/gram. There was, however, no improvement in $\mathrm{HbA}_{1 \mathrm{c}}$, which showed little change from $7.2 \%$ to $7.4 \%$. ERP was performed in May 2001, and abdominal plain CT immediately afterward; both showed that the protein plug had been eliminated from the pancreatic duct (Fig. 3). The patient has continued to take bromhexine hydrochloride, an $\mathrm{H}_{2}$-receptor antagonist, and digestive enzymes for 3 years, and despite his continued drinking, he has had no recurrence of pancreatitis. His investigation results are stable, with serum amylase $284 \mathrm{IU} / l$, urinary amylase $962 \mathrm{IU} / l$, fecal chymotrypsin 22.3 units/gram, and $\mathrm{HbA}_{\mathrm{lc}} 7.0 \%$, and there has been no protein plug reformation at MRCP.

\section{Discussion}

Complications in the thoracic cavity associated with chronic pancreatitis include pleural effusion, pericardial effusion and mediastinal pancreatic pseudocysts. Of these, reports of mediastinal pancreatic pseudocysts are rare. This complication was first reported by Edlin in 1951 (1), and less than 50 cases have been reported thus far (2). Cameron has postulated that a mediastinal pancreatic pseudocyst is the result of pancreatic juice leaking through a rupture of the posterior pancreatic duct, caused by pancreatitis (3), and then entering the mediastinum from the posterior peritoneal cavity, but there has not been a report of a mediastinal pancreatic pseudocyst resulting from obstruction of the pancreatic duct by a protein plug. Generally, mediastinal pancreatic pseudocyst is treated surgically by internal and external fistulectomy in patients who show little improvement with initial treatment, develop severe infection, or require emergency treatment. Improvement of a mediastinal pancreatic pseudocyst with conservative treatment $(4,5)$, or spontaneous improvement (6), has been reported in patients who did not require surgical treatment because they were generally in good health. As the present patient was also in good general health, the initial treatment comprised antibiotics, a proteolytic enzyme inhibitor, and an $\mathrm{H}_{2}$-receptor antagonist. After about 3 weeks of treatment, serum and urinary amylase 

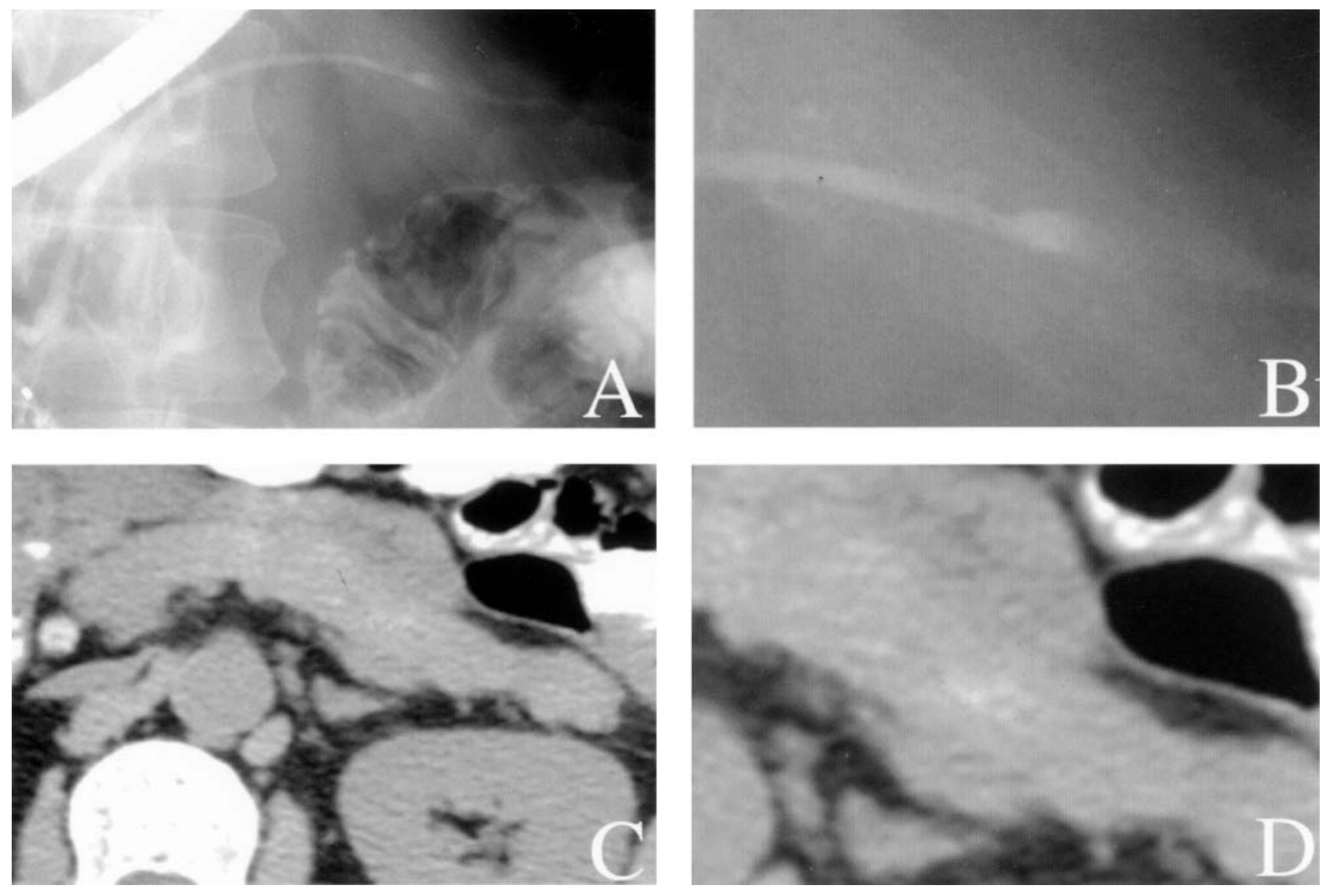

Figure 3. Endoscopic retrograde pancreatography (ERP) image and abdominal plain computed tomography (CT) taken immediately after ERP, after 5 months of treatment with bromhexine hydrochloride. (A, B) ERP: the dilation of the pancreatic duct in the body has improved and the small transparent object that was suggestive of a protein plug has disappeared. The irregularity of the main pancreatic duct lumen has also improved. (C, D) Abdominal plain CT taken immediately after ERP: there is less accumulation of contrast material in the pancreatic duct and the transparent object within the lumen has also disappeared.

concentrations had improved, and all radiological evidence of the mediastinal pancreatic pseudocyst, pleural effusions, and posterior peritoneal pancreatic pseudocysts had disappeared. Although patients reportedly require 4-14 months of conservative treatment to eliminate such cysts $(4,5)$, those in the present patient disappeared rapidly, probably because the protein plug that was temporarily obstructing the pancreatic duct like a check-valve was dislodged or removed by an unknown mechanism.

In cases of alcoholic chronic pancreatitis, continuous drinking by the patient is considered to increase the protein concentration of the pancreatic juice $(7,8)$ and thus its viscosity $(9,10)$, leading to formation of a protein plug in the pancreatic duct $(11,12)$ and recurrent attacks of pancreatitis. Attempts have been made to treat such patients with secretin (13), and endoscopic removal of the pancreatic juice and protein plug (14), but it is difficult to achieve a permanent effect.

Bromhexine hydrochloride is an alkaloid which is developed from an active ingredient of adhatoda vasica, a crude preparation discovered in India. Its pharmacological activities include increasing serous secretions from the bronchial mucosa (15), and fragmentation of the acid mucopolysaccharide involved in the viscosity of sputum (16). It is widely used clinically as an expectorant, and has been shown to be effective for the symptoms of dry eyes and dry mouth associated with Sjögren's syndrome by increasing lacrimation and salivation $(17,18)$. Bromhexine hydrochloride has also been shown to have a high transfer to, and affinity for, the pancreas in rats and dogs, and to produce low-viscosity mucus by directly acting on mucus-producing cells (19). Thus bromhexine hydrochloride enhances the function of a wide range of exocrine glands. In clinical use, administration of bromhexine hydrochloride to a patient with recurrent pancreatitis associated with a mucin-producing pancreatic tumor produced remission of symptoms and signs, normalization of pancreatic enzymes and a reduction in the viscosity of the pancreatic juice (20), thus demonstrating its solubilizing effect on mucous protein. A similar effect has been reported in a patient with a mucin-producing bile duct tumor 
(21). In another patient with non-alcoholic chronic pancreatitis, a protein plug disappeared after bromhexine hydrochloride was administered for four and a half months (22).

Anticipating a beneficial result from the mucolytic effect of bromhexine hydrochloride on the pancreatic juice, we added it $(12 \mathrm{mg} /$ day p.o.) to the present patient's existing regimen of camostat mesilate, $\mathrm{H}_{2}$-receptor antagonist and digestive enzymes, because he was unable to stop drinking. This led to improvement in his epigastric and back pain, and in both the concentration of pancreatic enzymes and pancreatic exocrine function. No improvement in pancreatic endocrine function was observed, however. ERP demonstrated elimination of the protein plug and improvement in the irregular outline of the lumen of the main pancreatic duct. Overall, these results indicate that bromhexine hydrochloride reduced the viscosity of mucus by acting on the acinar cells (i.e. the pancreatic exocrine gland) and thus improved the congestion of the pancreatic juice, leading to improvement in clinical symptoms, pancreatic enzymes and pancreatic exocrine function, as well as dissolution of the protein plug. Currently the patient continues to take bromhexine hydrochloride and remains free of recurrence of pancreatitis despite his continued drinking.

In alcoholic chronic pancreatitis, it is considered that the patient's continuous drinking results in recurrent attacks of pancreatitis because of the increased protein concentration in the pancreatic juice, which leads to the formation of a protein plug in the pancreatic duct. Bromhexine hydrochloride has a high affinity for pancreatic tissue, causing the acinar cells to secrete low-viscosity pancreatic juice, which improves congestion of the juice. Although the importance of abstaining from alcohol goes without saying, the outcome in the present case suggests that bromhexine hydrochloride is a potential new treatment for conditions in which increased viscosity of the pancreatic juice is associated with attacks of pancreatitis.

\section{References}

1) Edlin P. Mediastinal pseudocyst of the pancreas - a case report and discussion. Gastroenterology 17: 96-102, 1951.

2) Rose EA, Haider M, Yang SK, Telmos AJ. Mediastinal extension of a pancreatic pseudocyst. Am J Gastroenterol 95: 3638-3639, 2000.

3) Cameron JL. Chronic pancreatic ascites and pancreatic pleural effusions. Gastroenterology 74: 134-140, 1978.

4) Hayasaka $K$, Tanaka $K$, Mutoh $H$, et al. CT evaluation of mediastinal pancreatic pseudocyst. Jpn J Clin Radiol 40: 957-960, 1995 (in Japanese, Abstract in English)
5) Mutoh M, Iketani S, Saito Y, et al. Two cases of mediastinal pancreatic pseudocyst that were improved with conservative treatment. Nippon Shokakibyo Gakkai Zassi 93: 57-63, 1996 (in Japanese).

6) Satake K, Cho K, Sowa M, et al. Demonstration of a pancreatic fistula by endoscopic pancreatography in a patient with chronic pleural effusion. Am J Surg 136: 390-392, 1978.

7) Estevenon JP, Sarles H, Figarella C. Lactoferrin in the duodenal juice of patients with chronic calcifying pancreatitis. Scand J Gastroenterol 10: 327-330, 1975.

8) Wakabayashi A, Takeda Y. The behavior of mucopolysaccharide in the pancreatic juice in chronic pancreatitis. Am J Dig Dis 21: 607-612, 1976.

9) Harada H, Takeda M, Yabe H, et al. The hexosamine concentration and output in human pure pancreatic juice in chronic pancreatitis. Gastroenterol Jpn 15: 520-526, 1980.

10) Tympner F, Rösch W. Viscosity and trypsin activity of pure pancreatic juice in chronic pancreatitis. Acta Hepatogastroenterol 25: 73-76, 1978.

11) Sarles H, Sarles CJ, Camatte R, et al. Observations on 205 confirmed cases of acute pancreatitis, recurring pancreatitis, and chronic pancreatitis. Gut 6: 545-559, 1965.

12) Nakamura $K$, Sarles H, Payan H. Three dimensional reconstruction of the pancreatic ducts in chronic pancreatitis. Gastroenterology 62: 942949, 1972.

13) Tympner F, Rosch $\mathrm{W}$. The treatment of chronic recurrent pancreatitis with depot secretin - a preliminary report. Hepato-Gastroenterol 33: 159-162, 1986.

14) Harada H, Miyake H, Miki H, Kobayashi T, Sasaki T, Kimura I. Role of endoscopic elimination of protein plugs in the treatment of chronic pancreatitis. Gastroenterol Jpn 17: 463-468, 1982.

15) Engelhorn R, Puschmann S. Pharmakologische untersuchungen uber eine substanz mit sekretolytischer. Arzneimittelforschung 13: 474-480, 1963 (in German).

16) Bruce RA, Kumar V. The effect of a derivative of vasicine on bronchial mucus. Br J Clin Pract 22: 289-292, 1968

17) Frost-Larsen K, Isager H, Manthorpe R. Sjögren's syndrome treated with bromhexine - a randomised clinical study. Br Med J 1: 15791581, 1978.

18) Magid E, Frost-Larsen K, Isager H, Manthorpe R, Prause JU. Serum isoamylases in Sjögren's syndrome - concentration levels and intraindividual variation. Scand J Rheumatol 12: 129-132, 1983.

19) Chan JH, Watanabe $S$, Toki $F$, et al. Studies on the transfer of bromhexine- $\mathrm{HCl}\left(\right.$ Bisolvon $^{\circledR}$ ) from the blood to the pancreas in the rat and the dog. Suizo 8: 403-407, 1993 (in Japanese, Abstract in English).

20) Chan JH, Takeuchi T. Effect of bromhexine in the treatment of pancreatitis accompanied by a mucin producing pancreatic tumor. Tan to Sui 12: 281-285, 1991 (in Japanese).

21) Shinohara $Y$, Fukuda S, Takeda $K$, et al. A case of mucin-producing bile duct tumor which responded to bromhexine hydrochloride treatment and radiotherapy. Tando 7: 527-534, 1993 (in Japanese, Abstract in English).

22) Noda A, Ibuki E, Murayama H, Hase S. Bromhexine hydrochloride eliminates protein plugs and relieves attacks of pancreatitis. Pancreas 15: 209-211, 1997. 